\title{
HLA-C in Preeclampsia: a Pilot Study to Propose a Tolerogenic Treatment
}

César Lucio-García, ${ }^{1}$ Cynthia Ayerim Lucio-García, ${ }^{1}$ Arely Sarai Alonso-Barreto, ${ }^{2}$ María del Socorro Camarillo-Romero, 1,3 Cristian Fabian Layton-Tovar,4 Deisy Julieth Abril-Riaño, ${ }^{2}$ Hugo Mendieta-Zerón. $1,2,6$

\begin{abstract}
Background: The serum level of soluble Human Leukocyte Antigen-antigen-D Related (HLA)-(DR) (sHLA-DR) may appear as a useful parameter to monitor maternal immune response during pregnancy. Objective: The aim was to compare HLA-G serum levels in patients with or without preeclampsia. Methods: Pregnant women seen at the "Mónica Pretelini Sáenz" Maternal-Perinatal Hospital (HMPMPS) were recruited at their first visit. Two groups were conformed: a) women with healthy pregnancies, and b) women with preeclampsia. The patients' sociodemographic and laboratory data were introduced into the SPSS software program. HLA-G quantification was performed in peripheral blood samples through the Enzyme-linked Immunosorbent Assay (ELISA) method. Results: The total number of women seen was 16 (mean age, $24 \pm 8$ years), eight healthy women (mean age, $22 \pm 3$ years) and eight women with preeclampsia (mean age, $27 \pm 7$ years). Women with preeclampsia were older, heavier, had higher levels of Systolic Blood Pressure (SBP), Diastolic Blood Pressure (DBP), Mean Arterial Pressure (MAP), and referred less sexual intercourse per week than healthy pregnant women. There was no difference in HLA-G levels. Conclusion: The sexual intercourse frequency is a major factor to develop preeclampsia and the serum HLA-G levels measured previous to the child delivery or cesarean are not different between women with or without preeclampsia.
\end{abstract}

Key Words: HLA-G; Preeclampsia; Risk Factors; Sexual Intercourse (Source: MeSH-NLM).

\section{Introduction}

Preeclampsia is currently a major issue of concern in the field of public health due to high mortality rates and maternal and perinatal morbidity, and this is particularly alarming, as these variables are found among indicators of social inequality. In Mexico, maternal mortality associated with preeclampsia is 5-9 times higher than in high-income countries. ${ }^{1}$ It has been hypothesized that the etiology of preeclampsia is based on immunology; thus, prolonged exposure to paternal sperm through sexual intercourse or through exposure to fetal antigens in a previous pregnancy may confer a protective effect. ${ }^{2}$ The protective effect of a previous birth is lost when the subsequent pregnancy is conceived with a new partner. 3 Preeclampsia is more common in primiparous women, or in the case of a new sexual partner. ${ }^{4}$

There are several theories that explain preeclamptic etiopathology, in their majority focusing on the placenta as the cause of ischemic disturbances, this due to poor immune adaptation, genetic predisposition, and the secretion of vascular factors that cause morphological changes in the placental endothelium. 5 on the other hand, among the hormonal factors that appear to induce preeclampsia, we find leptin. In fact, our group has reported that leptin levels $>40$ $\mathrm{ng} / \mathrm{mL}$ in the second trimester of pregnancy in women with obesity are predictors of preeclampsia. 6

During pregnancy, the fetus is a semi-allogeneic graft. The mechanisms by which the maternal immune system does not reject the fetus, despite the presence of paternal antigens, is not yet fully understood.?
Therefore, regulation of maternal immune response appears to be essential for the survival of the fetus. The loss of tolerogenic mechanisms may be involved in the cause of diseases associated with pregnancy, such as preeclampsia, IntraUterine Growth Retardation (IUGR), placenta previa, and the Hemolysis, Elevated Liver enzymes and Low Platelets (HELLP) syndrome. A common event in all of these disorders is inadequate trophoblast invasion of the maternal spiral arteries and poor placental perfusion in early pregnancy. ${ }^{8}$

Although the placenta acts as a barrier between maternal and fetal circulation, there is two-way cell traffic through this barrier. It has been shown that an increased number of fetal cells can be detected in maternal circulation in the case of preeclampsia. Human Leukocyte Antigens (HLA) class I, present on the cell surface of virtually all nucleated cells in the body, present antigenic peptides produced by the cell, which are recognized by cytotoxic T CD8 cells, whereas HLA class II are restricted to B cells, macrophages, dendritic cells, endothelial cells, and Antigen Presenting Cells (APC), which present antigenic peptides that are recognized by T-helper $\mathrm{CD}_{4}$ cells.?

Other mechanisms of tolerance induction occur in the fetal-maternal interface. Fetal villous cytotrophoblasts and syncytiotrophoblasts express nonclassical HLA-G and HLA-E, both of which can block the cytotoxicity of maternal Natural Killer (NK) cells.10 Soluble Human Leukocyte Antigen-G (SHLA-C) is considered essential in pregnancyassociated immune tolerance and in successful implantation, in such a way that, compared to healthy controls, serum levels of sHLA-G is lower in pregnancies complicated by preeclampsia. ${ }^{11-12}$

\footnotetext{
${ }^{1}$ Faculty of Medicine, Autonomous University of the State of Mexico (UAEMex), Mexico.

${ }^{2}$ Ciprés Grupo Médico S.C. (CGM), Mexico.

${ }^{3}$ Medical Sciences Research Center (CICMED), Autonomous University of the State of Mexico (UAEMex), Mexico.

${ }^{4}$ Coordinación de Hospitales de Alta Especialidad (CHAE), Secretaría de Salud, Mexico.

${ }^{5}$ Universidad El Bosque, Bogota, Colombia.

6 "Mónica Pretelini Sáenz" Maternal-Perinatal Hospital, Mexico.
}

About the Author: César Lucio García is a recently graduated MD, beginning his private clinical practice and preparing himself for a Master Degree Program. While student, in August 2017 he was selected for an academic visit in the Department of Robotic and Laparoscopic Surgery at the Moscow Clinical Scientific Center. 
Although the etiology of preeclampsia is unknown, a substantial number of studies favor a theory based on a maladapted immune system, with the more specific attributes of low levels of immune regulatory cells and low expression of HLA-G. The aim of this study was to compare the serum levels of HLA-G in patients with or without preeclampsia. ${ }^{13}$

\section{Methods}

This was a prospective, clinical and cross-sectional study, developed at the "Mónica Pretelini Sáenz" Maternal-Perinatal Hospital (HMPMPS), Health Institute of the State of Mexico, Toluca, Mexico, from September 2013 to November 2014

\section{Patients}

Pregnant women seen at the HMPMPS were recruited at their first visit. Two groups were conformed: a) women with healthy pregnancies, and b) women that developed preeclampsia. The definition of and criteria for preeclampsia were based on the diagnostic criteria outlined by the American College of Obstetrics and Cynecology (ACOG). ${ }^{14}$ The sample was considered at convenience during the year of follow-up. With a standard deviation of 3 , alpha risk of 0.0 , beta risk of 0.2 and assuming a drop-out rate of $10 \%, 7$ subjects were necessary per group to recognize as statistically significant a difference > 5 units in the HLA-C levels. Women with autoimmune, cardiovascular, and kidney diseases were excluded and those with incomplete medical information were discarded from the final analysis.

\section{Sociodemographic data}

All women were asked to respond to a complete medical history, including questions concerning risk factors for developing preeclampsia.

\section{Anthropometry}

The nursery staff of both hospitals trained in anthropometry registered the Body weight (BW) and blood pressure. The first was rounded off to the nearest $0.1 \mathrm{~kg}$ (Seca 700; Germany) and the second was recorded at each visit with a standard sphygmomanometer (Riester Big Ben ${ }^{\circ}$, Germany).

\section{Laboratory tests}

When a woman developed preeclampsia or when those with healthy pregnancies began with prodromic uterine contractions, blood samples were collected in Vacutainer ${ }^{\mathrm{TM}}$ tubes. Laboratory tests including blood type $(A, B, 0)$, albumin $(\mathrm{mg} / \mathrm{dl})$, creatinine $(\mathrm{mg} / \mathrm{dl})$, glucose $(\mathrm{mg} / \mathrm{dl})$, liver function tests (bilirubin, Lactate DeHydrogenase (LDH), ALanine aminoTransferase ((ALT), ASpartate aminoTransferase (AST)) transaminase, urea, uric acid (mg/dl) (Dimension ${ }^{\circledR}$ RXL Max; Dade Behring, Minneapolis, MN, USA), hematological parameters (Advia 120; Bayer Health), 24-h creatinine clearance $(\mathrm{ml} / \mathrm{min})$, and proteinuria ( $\mathrm{mg} / 24 \mathrm{~h}$ ) were carried out following International Federation of Clinical Chemistry and Laboratory Medicine (IFCC) criteria. A serum sample for HLA-C determination was stored at $-20^{\circ} \mathrm{C}$ until analysis.

\section{HLA-G}

HLA-G concentrations were determined with the Optical Density (OD) value by means of the Enzyme-Linked Immunosorbent Assay (ELISA) method (Abbiotec, cat: 251266) at $490 \mathrm{~nm}$ in ELX800 ${ }^{\mathrm{TM}}$ equipment (BioTek Instruments, Inc., USA), according to a standard (HLA-G 293 cell lysate, ABBIOTEC, cat. no. 409133). This process was conducted blinded at the Research Laboratory of Ciprés Grupo Médico S.C. (CGM), Toluca, Mexico.

\section{Ethics}

This study was approved by the Ethics and Research Committees of the HMPMPS (code 217B500402014016) and of the Hospital de la Mujer, Instituto Materno-Infantil del Estado de México (IMIEM) (17/12/2013) and was performed in accordance with the ethical standards laid down in the updated Declaration of Helsinki, Fortaleza, Brazil, 2013. Informed consent was obtained from the patient and guardian if the patient was $<18$ years of age.

\section{Statistics}

Statistical analysis was performed using SPSS ver.17 (SPSS, Inc. (hicago, USA) software. Differences in quantitative variables between the two groups were evaluated by the Mann-Whitney $U$ test. Spearman correlation was used between HLA-G levels and weeks of gestation. The risk of a previous familiar case of preeclampsia was evaluated through the odds Ratio (OR). A p value of $<0.05$ was considered statistically significant.

\section{Results}

The general characteristics of the patients are depicted in Table 1. Of a total of 25 patients who accepted to participate in the study (11 with preeclampsia and 14 controls), final analysis was carried out with 16 women (mean age, $24 \pm 8$ years): eight with uncomplicated pregnancies (mean age, $22.2 \pm 3.3$ years) and eight women with preeclampsia (mean age, $27.4 \pm 7.2$ years), who complied with all the sociodemographic and laboratory data (Figure 1). The decanted patients were due to having been attended as emergencies on weekends without having met the logistics of taking and storing the samples. Interestingly, in the group of cases, four had a direct relative who also suffered from preeclampsia and two patients had preeclampsia in a previous pregnancy. The OR for this last comparison was of $17(95 \% \mathrm{Cl}: 0.7378$ to $391.6992, \mathrm{z}: 1.770, \mathrm{p}$ $=0.0767)$.

Table 1. Clinical and Laboratorial Characteristics.

\begin{tabular}{lccc}
\hline Variable & $\begin{array}{c}\text { Healthy } \\
\text { pregnancies }\end{array}$ & Preeclampsia & $\boldsymbol{P}$ \\
Age (years) & $22.3 \pm 3.3$ & $27.4 \pm 7.2$ & 0.032 \\
BMI $\left(\mathrm{kg} / \mathrm{m}^{2}\right)$ & $26 \pm 2.7$ & $30.6 \pm 6$ & 0.032 \\
DBP $(\mathrm{mm} \mathrm{Hg})$ & $69.3 \pm 9.2$ & $94.2 \pm 4.2$ & 0.001 \\
Cohabitation time (years) & $3.17 \pm 3.61$ & $2.18 \pm 1.89$ & 0.727 \\
Cestational age (weeks) & $38.9 \pm 1.5$ & $37.4 \pm 2.8$ & 0.107 \\
HLA-G $(\mathrm{ng} / \mathrm{ml})$ & $78.3 \pm 14.3$ & $80.3 \pm 3.4$ & 0.674 \\
Hto $(\%)$ & $38.9 \pm 3.1$ & $36.2 \pm 3.6$ & 0.313 \\
MAP $(\mathrm{mm} \mathrm{Hg})$ & $83.1 \pm 8.8$ & $94.2 \pm 4.2$ & 0.001 \\
Pregnancies & $1.86 \pm 1.1$ & $1.82 \pm 1$ & 0.977 \\
SBP $(\mathrm{mm} \mathrm{Hg})$ & $110.7 \pm 9.2$ & $147.1 \pm 13.5$ & 0.001 \\
Sexual intercourse/week & $2.5 \pm 0.67$ & $1.2 \pm 0.9$ & 0.002 \\
\hline
\end{tabular}

Legend: a: mean $\pm S D$. BMI: body mass index, DBP: diastolic blood pressure, HLA-C: Human leukocyte antigens class $G$, Hto: hematocrit, MAP: mean arterial pressure, SBP: systolic blood pressure.

\section{Sociodemographic Data}

Table 2 shows the main social data of the patients. One half of the total population belonged to the Otomí indigenous group. Type of residency in the control as well as in the case group demonstrated the following distribution: inhabitants from an urban area in two cases $(25 \%)$, semiurban area in one $(12.5 \%)$, and from a rural area in five $(62.5 \%)$ cases.

Cohabitation time did not show significant differences $(p=0.727)$. In the control group, the source of sexual education derived exclusively from the school in one case $(12.5 \%)$, one $(12.5 \%)$ woman did not receive sexual education, one $(12.5 \%)$ referred another source, and five $(62.5 \%)$ received a mixture of information from both school and family. In the case group, the source of sexual education was the family in two (25\%) cases, a mixture of education from school and family in four $(50 \%)$ cases, and two (25\%) women did not refer any type of sexual education. Sexual intercourse was more frequent in healthy pregnancies than in those complicated by preeclampsia $(p, 0.01)$. Finally, aspirin intake and contraceptive method was confirmed in one (12.5\%) woman per group. 


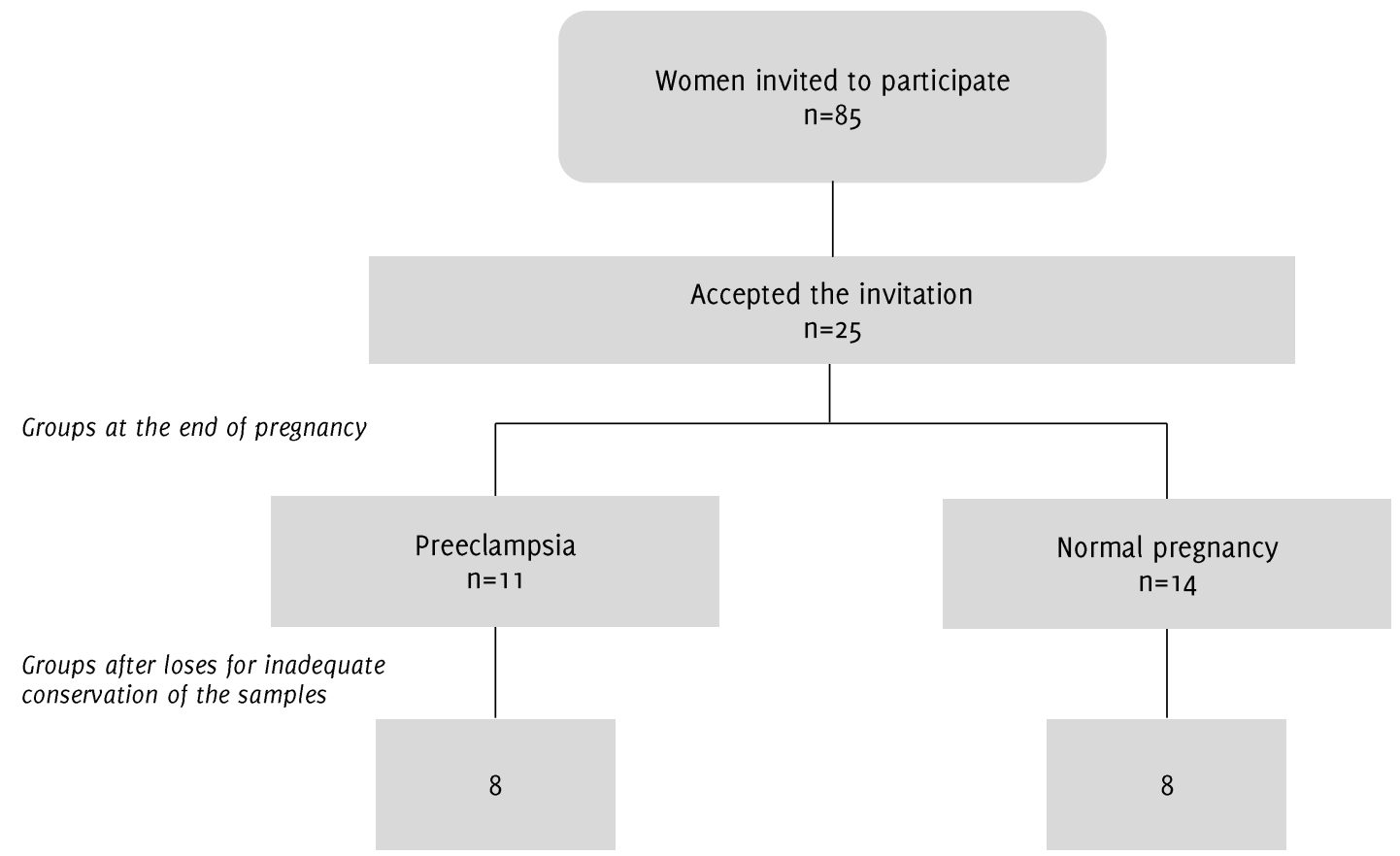

\section{Anthropometric and Laboratory Data}

The expected data that defines preeclampsia (Systolic Blood Pressure (SBP), Diastolic Blood Pressure (DBP), and Mean Arterial Pressure (MBP)) exhibited a statistical difference between both groups, as well as the known risk factors such as Body Mass Index (BMI). Unexpectedly, no difference was detected in the laboratory studies, including HLA-C levels $(78.3 \pm 14.3$ vs $80.3 \pm 3.4 \mathrm{ng} / \mathrm{mL}$ in healthy pregnancies and preeclamptic women respectively). Even more, by making a comparison of the HLA-G levels between primiparous and multiparous patients there wasn't any difference. By performing a Spearman correlation there was not a significant $r$ between HLA-C and gestational weeks ( $r=$ $0.104, p=0.744$ ). Ideally, a stratified analysis would be adequate to evaluate the effect of all the variables on the HLA-G levels but it is required to increase the $\mathrm{N}$.

In the group of preeclamptic women, the mean values for creatinine and uric acid were $1.02 \pm 0.52 \mathrm{mg} / \mathrm{dL}$ and $5.52 \pm 1.01 \mathrm{mg} / \mathrm{dL}$ respectively. These studies were not processes as a routine in normoevolutive pregnancies.

\section{Discussion}

From a general point of view, we have a preeclamptic population similar to that which is very well-known in the clinical setting. The difference in sexual intercourse per week is in line with several publications demonstrating the important role of sexual frequency and its association with the risk of developing preeclampsia. ${ }^{15-17}$

In another line, such as the expression of HLA-primarily limited to gestation, this has given rise to the hypothesis that HLA-G plays an important role in the immunological tolerance of the fetus through the mother. Previous publications have stated that SHLA-G expression in maternal circulation is associated with better pregnancy rates. ${ }^{18-23}$ Also, pregnancy success in In Vitro Fertilization (IVF) treatments improves by selecting the fertilized oocytes with the highest SHLA-G-positive culturemedium measurements. ${ }^{24-25}$
Table 2. Sociodemographic Information.

\begin{tabular}{|c|c|c|}
\hline Variable & Healthy pregnancies & Preeclampsia \\
\hline \multicolumn{3}{|l|}{ Education } \\
\hline No academic studies & $2(25 \%)$ & $0(0 \%)$ \\
\hline Primary school & $1(12.5 \%)$ & $2(25 \%)$ \\
\hline High school & $2(25 \%)$ & $4(50 \%)$ \\
\hline Preparatory school & $2(25 \%)$ & $2(25 \%)$ \\
\hline University & $1(12.5 \%)$ & $0(0 \%)$ \\
\hline \multicolumn{3}{|l|}{ Occupation } \\
\hline Student & $1(12.5 \%)$ & $1(12.5 \%)$ \\
\hline Worker & $1(12.5 \%)$ & $0(0 \%)$ \\
\hline Homemakers & $6(75 \%)$ & $6(87.5 \%)$ \\
\hline \multicolumn{3}{|l|}{ Marital status } \\
\hline Single & $1(12.5 \%)$ & $2(25 \%)$ \\
\hline Marriage & $1(12.5 \%)$ & $2(25 \%)$ \\
\hline Common-law & $6(75 \%)$ & $4(50 \%)$ \\
\hline \multicolumn{3}{|l|}{ Religion } \\
\hline Jehovah's Witness & $1(12.5 \%)$ & $0(0 \%)$ \\
\hline Atheist & $1(12.5 \%)$ & $0(0 \%)$ \\
\hline Catholics & $6(75 \%)$ & $6(100 \%)$ \\
\hline \multicolumn{3}{|c|}{ Income/month (US dollars) } \\
\hline$<150$ & $7(87.5 \%)$ & $6(75 \%)$ \\
\hline $150-300$ & $1(12.5 \%)$ & $1(12.5 \%)$ \\
\hline $300-600$ & $0(0 \%)$ & $1(12.5 \%)$ \\
\hline
\end{tabular}

In our study, contrary to what was expected, there was no statistical difference between women with preeclamptic and healthy pregnancies. It is noteworthy that serum samples have shown to be reproducible in relation to SHLA-C measurements. ${ }^{26}$ In the majority of the studies, SHLA-C 
has been determined with a commercially available sHLA-G ELISA kit (Exbio Praha, A.S., Vestec, Czech Republic), based on the capture of the MEMG/9 antibody, capturing SHLA-G1/- $G_{5}$ in association with $\beta 2 \mathrm{~m}$ and a detecting antibody against $\beta 2 \mathrm{~m}$. Interestingly, the study by Wu et al. who failed to report an association, employed a different ELISA assay, one with a higher limit of detection compared with the Exbio kit. ${ }^{27}$ This could account for the differences in the results, whereas there is no obvious explanation for the reported lack of association in the study by Zheng et al., who examined children with atopic asthma and positive controls. ${ }^{28}$ In a study conducted by Rizzo et al., SHLA-G1 and HLA-G5 were determined by performing two different ELISA assays: one capturing both SHLA-G 1 and HLA-G5, and one capturing only HLA-G $\mathrm{G}_{5}$ by the use of the monoclonal antibody (mAb) $5 A 6 \mathrm{G} 7$, which is specific for HLA-G5/-G6.19 Surprisingly, this showed that women with severe preeclampsia had significantly higher levels of soluble HLA-G5 than women with uncomplicated pregnancies. In the previously mentioned study, there was a trend toward lower sHLA-G1 expression in women with severe preeclampsia. ${ }^{19}$

Based on recent studies, we speculated that HLA-G might be involved in patients with preeclampsia from a Mexican population. This hypothesis was not verified and, although the sample was small, if there was a strong influence of the HLA-G levels in the pathogenesis of preeclampsia, this difference should be evident, such as that of leptin in the case of morbid obesity in the second trimester of pregnancy as a possible predictor for preeclampsia. ${ }^{6}$ Our results are in accordance with Biyik but the information that points out the relation of lower HLA$G$ levels and a higher risk of preeclampsia is also present. ${ }^{29-30}$ A very important item to be considered is the putative serum HLA-G variability by trimester and the genetic interaction between the child and the mother. $31-32$

The role of genetics might not be surprising in the effects of HLA-G; for example, polymorphisms in the HLA-G gene and HLA-G expression levels have been linked with reproductive failure and preeclampsia. Several studies have found that the 14 ins allele is associated with decreased levels of SHLA-G in blood plasma, while a few studies found no association.27-28, 33-34 Furthermore, a recent study even revealed a significant association between HLA-G genotype and the amount of SHLA-G in seminal plasma. 35

A clear limitation of this study is the low number of patients; this fact reflects the clinical reality in many Gyneco-Obstetrical Hospitals that faces loses in the follow up of risk patients. Additionally, the SHLA-G concentration during pregnancy must be a mixture of contributions from the mother, most probably from maternal immune cells, and from fetal trophoblast cells in the placenta. ${ }^{36}$ Besides the small sample size, other limitations are the lack of control of confounders in statistical analysis and the absence of a full immunological panel (HLA of the father and mother, cytokines, etc.) that could contribute to discern the interactions among them and HLA-G. Special mention is the fact that the ideal design must be a cohort, longitudinal study, to perform several quantifications of HLA-G, cytokines, etc.

From our results, the main risk factor for preeclampsia is the frequency of sexual intercourse. Although the antecedent of a previous woman affected in the family of the patient was near to reach statistical significance. Thus, a screening flowchart and a preventive treatment could be designed. First, the characterization of the immunological status including inflammatory cytokines of a woman at high risk of preeclampsia since the beginning of pregnancy might be a good maternal health target.

Due to the inadmissible worldwide maternal mortality caused by preeclampsia/eclampsia, we propose a new treatment aimed at the tolerance for paternal antigens in patients at risk (obesity, preeclampsia in a previous pregnancy, primiparous women and those with low sexual intercourse (e. g. in cases when the father is a worker that migrates to another Country) (Figure 2). First, from a sample of paternal peripheral blood, the leukocytes should be separated and subjected to a freeze-drying process. After standardization of the number of cells by extraction and its corresponding amount of RNA the pellet would be diluted in saline solution. Second, periodical subcutaneous injections should be administered to the mother at high risk of preeclampsia.

Figure 2. Candidate Pregnant Woman for a Paternal Immunotolerance Scheme.

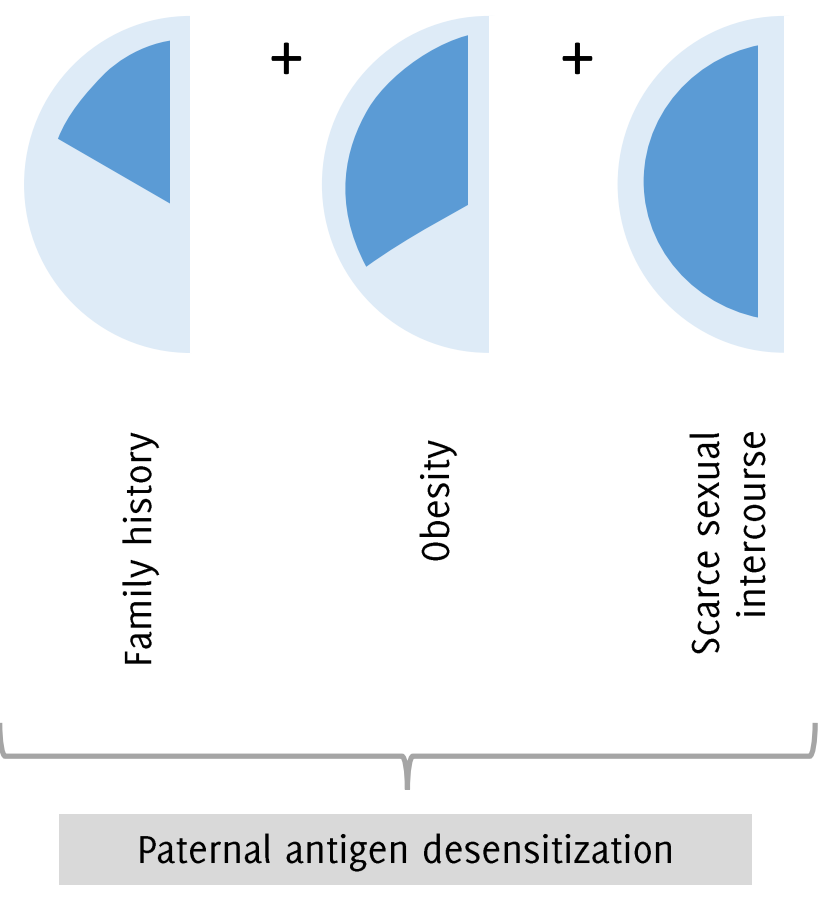

This is clear from this general idea the impossibility to know a priori the quantity $(\mu \mathrm{L})$ of solution to elute the sample preserving the antigenic properties, neither the doses to administer subcutaneously nor the period of time to do it but following a Taguchi method approach the standardization process could be reached. 37 Notwithstanding some ethical considerations should be taken into account, as the possibility to be immersed in paternal discrepancies.

Our results can be summarized as follows: family history of preeclampsia and the frequency of sexual intercourse are high-risk factors to develop preeclampsia. This reinforces the notion of a genetic background and the possibility to modify through an immunotolerance phenomenon the non-desired evolution. Future research questions must find the genes of the preeclampsia inheritance.

Any maternal death is a catastrophic event leading to orphaned children, family disintegration and social weakness. It is urgent the need to have an affordable and efficacious preventive treatment, but we can start with the design of a Preeclampsia Risk Scale that includes and assigns different points to the pre-pregnancy Body Mass Index (BMI), frequency of sexual intercourse, interleukin levels, familial cases of preeclampsia, etc.

Finally, we believe that a grant call from the World Health Organization (WHO) or from one or more high-income countries aimed at the reduction of the cases of preeclampsia based on the immune response could make a big difference in the maternal mortality. 


\section{References}

1. Velasco-Murillo V, Navarrete-Hernández E. [Maternal mortality in the IMSS: an analysis from the perspective of mortality and lethality]. Cir Cir 2006 Jan-Feb;74:21-6. spanish

2. Dekker CA, Sibai BM. The immunology of preeclampsia. Semin Perinatol 1999 Feb;23:24-33

3. Saftlas AF, Levine RJ, Klebanoff MA, Martz KL, Ewell MG, Morris CD, et al. Abortion, changed paternity, and risk of preeclampsia in nulliparous women. Am J Epidemio 2003 Jun;157:1108-14.

4. Caber LW, Spargo BH, Lindheimer MD. Renal pathology in pre-eclampsia. Baillieres Clin Obstet Gynaecol 1994 Jun;8:443-68.

5. Paller MS. Hypertension in pregnancy. J Am Soc Nephrol 1998 Feb;9:314-21.

6. Mendieta Zerón H1, García Solorio VJ, Nava Díaz PM, Garduño Alanís A, Santillán Benítez JG, Domínguez Carcía V, et al. Hyperleptinemia as a prognostic factor for preeclampsia: a cohort study. Acta Medica (Hradec Kralove) 2012;55:165-171.

7. Muñoz-Suano A, Hamilton AB, Betz AC. Cimme shelter: the immune system during pregnancy. Immunol Rev 2011 May;241:20-38.

8. Sado T, Naruse $K$, Noguchi T, et al. Inflammatory pattern recognition receptors and their ligands: factors contributing to the pathogenesis of preeclampsia. Inflamm Res 2011 Jun;60:509-20.

9. Rocha N, Neefjes J. MHC class II molecules on the move for successful antigen presentation. EMBO I 2008 Jan; 27:1-5.

10. Tilburgs T, Scherjon SA, Claas FHJ. Major histocompatibility complex (MHC) mediated immune regulation of decidual leukocytes at the fetal-maternal interface. Reprod Immunol 2010 May;85:58-62.

11. Roussev RG, Coulam CB. HLA-C and its role in implantation (review). J.Assist. Reprod. Genet. 2007 Jul;24:288-295.

12. Hviid TV. HLA-C in human reproduction: aspects of genetics, function and pregnancy complications. Hum. Reprod. Update 2006 May-Jun;12:209-232.

13. Saito S, Sakai M, Sasaki $Y$, Nakashima A, Shiozaki A. Inadequate tolerance induction may induce pre-eclampsia. J Reprod Immunol 2007 Dec;76:30-9.

14. ACOC Committee on Obstetric Practice. ACOC practice bulletin. Diagnosis and management of preeclampsia and eclampsia. Number 33, January 2002. American College of Obstetricians and Gynecologists. Int J Gynaecol Obstet. 2002 Apr;77:67-75. 15. Saftlas AF, Rubenstein L, Prater K, Harland KK, Field E, Triche E. Cumulative exposure to paternal seminal fluid prior to conception and subsequent risk of preeclampsia. | Reprod Immunol 2014 Mar;101-102:104-110.

16. Olayemi O, Strobino D, Aimakhu C, Adedapo K, Kehinde A, Odukogbe AT, et al. Influence of duration of sexual cohabitation on the risk of hypertension in nulliparous parturients in Ibadan: A cohort study. Aust N Z J Obstet Gynaecol 2010 Feb;50:40-4. 17. Kho EM, McCowan LME, North RA, Roberts CT, Chan E, Black MA, et al. Duration of sexual relationship and its effect on preeclampsia and small for gestational age perinatal outcome. J Reprod Immunol 2009 0ct;82:66-73.

18. Chaiworapongsa T, Romero R, Espinoza J, Bujold E, Mee Kim Y, Conçalves LF, et al. Evidence supporting a role for blockade of the vascular endothelial growth factor system in the pathophysiology of preeclampsia. Am J Obstet Cynecol 2004 Jun;190:1541-7.

19. Rizzo R, Andersen AS, Lassen MR, Sørensen $H C$, Bergholt $T$, Larsen $M H$, et al. Soluble human leukocyte antigen- $C$ isoforms in maternal plasma in early and late pregnancy. Am J Reprod Immunol 2009 Nov;62:320-38.

20. Yie S, Li L, Li Y, Librach C. HLA-C protein concentrations in maternal serum and placental tissue are decreased in preeclampsia. Am | Obstet Gynecol 2004 Aug:191:525-9. 21. Steinborn A, Varkonyi T, Scharf A, Bahlmann F, Klee A, Sohn C. Early detection of decreased soluble HLA-C levels in the maternal circulation predicts the occurrence of preeclampsia and intrauterine growth retardation during further course of pregnancy. Am J Reprod Immunol 2007 Apr;57:277-86.
22. Yie S, Taylor RN, Librach C. Low plasma HLA-C protein concentrations in early gestation indicate the development of preeclampsia later in pregnancy. Am J Obstet Cynecol 2005 Jul; 193:204-8.

23. Hackmon R, Koifman A, Hyodo $H$, Glickman $H$, Sheiner $E$, Geraghty DE. Reduced third-trimester levels of soluble human leukocyte antigen $G$ protein in severe preeclampsia. Am J Obstet Gynecol 2007 Sep;197:255.e1-5.

24. Vercammen Ml, Verloes A, Van de Velde H, Haentjens P. Accuracy of soluble human leukocyte antigen-C for predicting pregnancy among women undergoing infertility treatment: meta-analysis. Hum Reprod Update 2008 May-Jun; 14:209-218. 25. Kotze D, Kruger TF, Lombard C, et al. The effect of the biochemical marker soluble human leukocyte antigen $C$ on pregnancy outcome in assisted reproductive technology--a multicenter study. Fertil Steril 2013 Nov;100:1303-9.

26. Rudstein-Svetlicky N, Loewenthal R, Horejsi V, Gazit E. HLA-C levels in serum and plasma. Tissue Antigens 69 Suppl 2007 Apr;1:140-142.

27. Wu FX, Wu LI, Luo XY, Tang Z, Yang MH, Xie CM, et al. Lack of association between HLA-C 14-bp polymorphism and systemic lupus erythematosus in a Han Chinese population. Lupus 2009 Dec; 18:1259-66.

28. Zheng XQ, Li CC, Xu DP, Lin A, Bao WG, Yang CS, Yan WH. Analysis of the plasma soluble human leukocyte antigen- $C$ and interleukin-10 levels in childhood atopic asthma. Hum Immunol 2010 0ct; 71:982-7.

29. Bıyık I. Maternal serum soluble HLA-C in complicated pregnancies. I Matern Fetal Neonatal Med. 2014 Mar:27:381-4.

30. O'Brien M, McCarthy T, Jenkins D, Paul P, Dausset J, Carosella ED, et al. Altered HLA-C transcription in pre-eclampsia is associated with allele specific inheritance: possible role of the HLA-G gene in susceptibility to the disease. Cell Mol Life Sci. 2001 Nov; $58: 1943-9$

31. Darmochwal-Kolarz D, Kolarz B, Rolinski J, Leszczynska-Corzelak B, Oleszczuk J. The concentrations of soluble HLA-C protein are elevated during mid-gestation and decreased in pre-eclampsia. Folia Histochem Cytobiol. 2012 Jul;50:286-91.

32. Dahl M, Klitkou L, Christiansen OB, Djurisic S, Piosik ZM, Skovbo P, et al. Human leukocyte antigen (HLA)-C during pregnancy part II: associations between maternal and fetal HLA-C genotypes and soluble HLA-C. Hum Immunol. 2015 Apr;76:260-71. 33. Hviid TV, Rizzo R, Melchiorri L, Stignani M, Baricordi OR. Polymorphism in the $5^{\prime}$ Upstream Regulatory and ' $3^{\prime}$ Untranslated Regions of the HLA-C Gene in Relation to Soluble HLA-C and IL-10 Expression. Hum Immunol. 2006 Jan-Feb;67:53-62. 34. Rizzo R, Hviid TV, Covoni M, Padovan M, Rubini M, Melchiorri L, et al. HLA-C genotype and HLA-C expression in systemic lupus erythematosus: HLA-C as a putative susceptibility gene in systemic lupus erythematosus. Tissue Antigens 2008 Jun; 71:520-9. 35. Twito T, Joseph J, Mociornita A, Rao V, Ross H, Delgado DH. The 14-bp deletion in the HLA-C gene indicates a low risk for acute cellular rejection in heart transplant recipients. J Heart Lung Transplant 2011 Jul;30:778-82.

36. Chen XY, Yan WH, Lin A, Xu HH, Zhang JG, Wang XX. The 14 bp deletion polymorphisms in HLA-C gene play an important role in the expression of soluble HLA$C$ in plasma. Tissue Antigens 2008 0ct;72:335-41.

37. Dahl M, Perin TL, Djurisic S, Rasmussen M, Ohlsson 」, Buus $S$, et al. Soluble human leukocyte antigen-C in seminal plasma is associated with HLA-C genotype: possible implications for fertility success. Am J Reprod Immunol 2014 Jul; $72: 89-105$.

38. Dahl M, Djurisic S, Hviid TVF. The many faces of human leukocyte antigen-C: relevance to the fate of pregnancy. I Immunol Res 2014;2014:591489.

39. Rao RS, Kumar CG, Prakasham RS, Hobbs PJ. The Taguchi methodology as a statistical tool for biotechnological applications: a critical appraisal. Biotechnol J. 2008 Apr;3:510-23.

\footnotetext{
Acknowledgments

Authors thank Irazú Contreras García PhD., José Antonio Estrada PhD., María del Carmen Colín Ferreyra PhD., Q.F.B. Fernando Mendieta Alcántara for the kindly support with solutions and laboratorial implements and Mrs. Maggie Brunner M.A., for her excellent help with the English style correction. Conflict of Interest Statement it Funding

The Authors have no funding, financial relationships or conflicts of interest to disclose.

\section{Author Contributions}

Conception and design the work/idea: HMZ. Collect data / obtaining results: CLG, CALG, ASAB, CFLT, DJAR. Analysis and interpretation of data, Approval of the final version: CLG, CALG, ASAB, MSCR, CFLT, DJAR, HMZ. Write the manuscript: CLG, CALG, ASAB, MSCR, CFLT, HMZ. Critical revision of the manuscript: MSCR, HMZ. Obtaining financing: MSCR, HMZ. Statistical advice: HMZ. Administrative or technical advice: CFLT, DJAR.

Cite as:

Lucio-García C, Lucio-García CA, Alonso-Barreto AS, Camarillo-Romero MS, Layton-Tovar CF, Abril-Riaño DJ, et al. HLA-G in preeclampsia: a pilot study to propose a tolerogenic treatment. Int J Med Students. 2018 May-Aug;6(2):56-60.
}

This work is licensed under a Creative Commons Attribution 4.0 International License 